\title{
METÁFORAS PARA LA FORMACIÓN DE LA CATEGORÍA DE NÚMERO PLURAL EN LAS LENGUAS CRIOLLAS
}

\author{
Mario Portilla
}

\begin{abstract}
RESUMEN
El presente trabajo muestra cómo la gramaticalización de categorías lingüísticas abstractas se materializa en las lenguas particulares por medio de procesos de extensión metafórica o analógica con una fuerte base cognitiva, mediante el análisis del surgimiento de la categoría de número plural en las lenguas criollas.

Palabras clave: Metáfora, plural, lenguas criollas, inglés criollo de Limón.
\end{abstract}

ABSTRACT

This article explains how grammaticalization of abstract linguistic categories crystallizes in specific languages through processes of metaphoric or analogical extension with a strong cognitive basis, analizing the emergence of the plural number category in the creole languages.

Key words: Metaphor, plural, Creole languages, Limon Creole English.

\section{La metáfora en la construcción de categorías gramaticales}

La teoría tipológico-funcional, tal como ha sido desarrollada por Talmy Givón de la Universidad de Oregón y otros colaboradores, reconoce que el cambio metafórico de los prototipos categoriales constituye la esencia de la gramaticalización (cf. Givón 1984: 19 y passim). La gramaticalización de las categorías lingüísticas abstractas se materializa en las lenguas particulares por medio de la implementación de procesos de extensión metafórica o analógica. El concepto de categorías difusas y no discretas, expresadas por prototipos, como es sabido, es tomado directamente de Wittgenstein (1953).

Dr. Mario Portilla. Profesor Catedrático de la Universidad de Costa Rica. San José, Costa Rica. Correo electrónico: marioportilla2000@yahoo.com

Recepción: 20- 11- 2009

Aceptación: 11- 01- 2009 
Un ejemplo concreto muy ilustrativo de las operaciones de extensión metafórica se puede ver en el uso del lexema ir (realizar un movimiento hacia un lugar), en inglés y muchas otras lenguas, como el marcador de la categoría de tiempo futuro. Givón (1985: 20) define esta operación de extensión metafórica, que va de lo espacial a lo temporal, de la siguiente manera:

(a) "Going to a place where one will do X > moving to a time when one will do X".

El escogimiento mismo del lexema que expresará y conformará una determinada categoría lingüística depende obviamente de la metáfora elegida. También, la definición de la propia categoría a través del tiempo (es decir, la definición de las propiedades características de esta) dependerá del uso pragmático que se le dé al operador morfosintáctico que expresa la categoría. A su vez, este uso permite activar otros procesos de extensión metafórica.

Lo anterior se puede ilustrar con una breve descripción diacrónica del surgimiento y desarrollo de la categoría del llamado futuro simple en español. Como es sabido, en esta lengua, al igual que en otras romances, las formas del futuro simple provienen de la combinación del infinitivo con el verbo haber, el cual significaba originalmente tener, tener que (hablaré < hablar $+[\mathrm{h}] \mathrm{e}$; hablarás $<$ hablar $+[\mathrm{h}] \mathrm{as}$; etc.). ${ }^{2}$ Es decir, el verbo haber tenía, en un principio, el sentido de poseer como verbo pleno y luego un sentido deóntico como auxiliar.

El proceso metafórico implícito en la construcción de esta categoría es el siguiente:

(b) Tener (haber) el control de un evento > tener (haber) la certeza de realizar un evento en el futuro > tener (haber de) la obligación de realizar un evento en el futuro $>$ el evento se realizará (realizar ha) en el futuro.

El modo en que el cambio metafórico operó en español antiguo puede ser ilustrado con el siguiente ejemplo del Poema de Cid:

(1) E cras a la mañana I ir vos hedes sin falla. (1808) ${ }^{3}$

El cambio de significado del verbo haber en el verso anterior impica la confusión del sentido deóntico original con uno más bien temporal y predictivo:

(2) Y mañana temprano os habéis de ir sin falla $>$ Y mañana temprano os iréis sin falla.

Otro ejemplo que ilustra tales propiedades características de esta categoría es el siguiente:

(3) Oy es dia bueno I e mejor sera $[<\operatorname{ser} h a]$ cras. (1686)

Así, pues, el verbo haber, por el proceso de extensión metafórica descrito antes, cambia el significado deóntico original para tomar un sentido más bien temporal y predictivo. Se convierte en un verbo auxiliar que expresa una categoría gramatical de tiempo futuro (es decir, expresa un evento que ha ocurrido en un momento posterior al momento de la enunciación). ${ }^{4}$

Actualmente en español, sin embargo, el llamado futuro simple, aunque naturalmente todavía permite expresar predicaciones de carácter temporal, se ha constituido en una categoría más prototípicamente modal. Se puede afirmar, pues, que el futuro simple constituye más bien una de las categorías del modo irrealis (es decir, expresa un evento cuya realización es incierta). ${ }^{5}$ 
El proceso metafórico que ha redefinido esta categoría puede ser expresado de la siguiente manera:

(c) Un evento ocurrirá en el futuro > un evento del futuro es incierto.

La noción de incertidumbre se convierte, entonces, en la propiedad central o más característica de esta categoría. El sentido temporal pasa a un segundo plano. Este cambio de enfoque de la categoría es lo que permite también poder expresar ciertas predicaciones referidas al tiempo presente, con el futuro simple, siempre y cuando estas tengan un sentido de incertidumbre. A continuación se presentan dos ejemplos de este uso prototípico modal, con una referencia al tiempo presente, que tiene futuro simple en la actualidad:

(4) - ¿Qué hora es? - No sé, serán como las cuatro.

(5) ¿Dónde estará el profesor que no ha llegado todavía?

Así, pues, las categorías gramaticales mismas serán redefinidas a través del tiempo por el uso pragmático que se da a los operadores. En este caso, por ejemplo, el llamado futuro simple ha pasado de ser una categoría temporal para convertirse en una categoría más bien modal.

Como se ha dicho antes, en el español actual no existe una categoría de tiempo futuro propiamente dicha. Esto no quiere decir, por supuesto, que no puedan expresarse predicaciones referidas al "tiempo futuro" por distintos medios, como el uso del mismo futuro simple (hablaré), del llamado futuro perifrástico (ir $+\mathrm{a}+$ infinitivo) (voy a hablar) (otra metáfora recurrente para esta categoría, como se ha dicho) y del presente (hablo).

Por último, el caso del futuro simple del español también ejemplifica el proceso diacrónico de gramaticalización de un marcador u operador morfosintáctico; es decir, el proceso por el cual un lexema se convierte en un marcador morfológico. Este proceso, aunque sea gradual, indefectiblemente terminará por oscurecer la metáfora que ha permitido construir la categoría gramatical misma.

Los siguientes ejemplos tomados del Poema del Cid muestran el cambio que ha sufrido el lexema haber ya en la Edad Media:

(6) D'aqui quito Castiella I pues que el rey he en ira. (219)

(7) ¡Ya cavalleros! I dezir vos he la verdad. (947)

(8) que yo dexar m'e morir, I que non quiero comer. (1029)

(9) antes perdere el cuerpo I e dexare el alma. (1022)

El ejemplo (6) muestra el uso de haber como verbo pleno con el sentido original de tener. En los ejemplos (7) y (8) haber funciona como un verbo auxiliar, el cual presenta todavía una cierta independencia respecto del verbo principal, aunque probablemente ya tuviera un carácter clítico. Como se nota, la colocación de haber separado del verbo principal está condicionada por la presencia de pronombres personales enclíticos (vos, me). En el ejemplo (9), haber aparece junto al verbo principial formando ya una sola palabra, tal como sucede actualmente. Ha dejado de ser un verbo auxiliar y se ha convertido en un afijo, un morfema trabado de carácter flexivo. 
En el proceso de gramaticalización de las categorías, los operadores que las expresan se modificarían siguiendo siempre el mismo orden:

(d) Morfema radical $>$ morfema independiente clítico $>$ morfema dependiente afijo.

En este caso concreto, el orden correspondiente del cambio de estatus del operador es el siguiente:

(e) Verbo pleno $>$ verbo auxiliar enclítico $>$ sufijo verbal.

El uso de metáforas para la conformación de categorías gramaticales en las lenguas del mundo es muy variado y a menudo se ha considerado inescrutable, en parte precisamente al cambio lingüístico sucesivo que muchas veces oscurece la motivación cognitiva, sensorial o lingüística que subyace al proceso de extensión metafórica.

\section{La categoría de plural en las lenguas criollas}

La llamada criollística o el estudio de las lenguas criollas surge como un campo prometedor para la comprensión del uso de la metáfora en la conformación de categorías gramaticales, debido a que, por definición, una lengua criolla constituye la nativización de una interlengua deficitaria de categorías morfosintácticas, los denominados pidgins.

Es común en los pidgins la eliminación de los marcadores morfológicos que expresan categorías gramaticales, como el número plural. Al tratarse de interlenguas, los pidgins simplemente omiten la distinción entre plural y singular, eliminando la categoría gramatical de número cuando esta exista en la lengua que sirve de base al pidgin. ${ }^{6}$ Por ello, es común que, si se ha perdido la categoría de número plural en las lenguas criollas, esta sea reinventada por los hablantes al nativizar el pidgin. ${ }^{7}$ La naturaleza de esta categoría será lógicamente distinta de su contraparte en la lengua de superestrato.

Las lenguas criollas presentan marcadores de plural que pueden tener tres orígenes distintos:

(i) El marcador de plural es un operador de esta categoría ya existente en alguna de las lenguas de sustrato. Ejemplos de este tipo de lenguas criollas son el palenquero (Colombia) y el holandés de Berbice (Guyana).

(ii) El marcador de plural se modela a partir del pronombre de 3 a persona plural en la misma lengua. El papiamento (Antillas holandesas) y el inglés criollo de Limón (Costa Rica) representan ejemplos de este caso.

(iii) El marcador de plural está relacionado con un cuantificador con el sentido de muchos y por medio de reduplicación. Este parece ser el caso de varios criollos de origen ibérico de Asia (Bakker 2002: 15). Por ejemplo, en el chabacano (criollo de base española de Filipinas), el plural de los sustantivos se marca por medio de la palabra manga (cf. tagalo manga [manah] 'marcador de plural', malayo bañak 'muchos') ${ }^{8} \mathrm{y}$ el de los adjetivos más raramente por medio de reduplicación (Holm 1989: 320). Esta marcación del plural parece tener como modelo el tagalo y el malayo (cf. Grant 2007: 178 y Crawfurd 1852:11). 


\section{La conformación de la categoría de plural en las lenguas criollas}

A pesar de que el marcador de plural tiene diversos orígenes en el ámbito de las lenguas criollas, como se verá más adelante, las propiedades características de la categoría misma parecen ser muy semejantes en esta clase de lenguas.

Precisamente, el análisis del caso concreto de la categoría de número plural en el inglés criollo de Limón podrá ilustrar los procesos de extensión metafórica que permiten la conformación de esta categoría. Se trata de procesos de extensión metafórica que parecen tener una base cognitiva bastante universal.

\subsection{La categoría de plural en el inglés criollo de Limón}

El inglés criollo de Limón es una lengua criolla de base inglesa, hablada especialmente en la costa atlántica de Costa Rica. Esta se encuentra muy relacionada genealógicamente con el inglés criollo de Jamaica.

En esta lengua, el número plural se expresa por medio de la partícula enclítica -dem (them) y se utiliza de manera selectiva bajo ciertas condiciones, que serán analizadas más adelante.

El siguiente ejemplo muestra el uso del marcador de plural en un caso prototípico: ${ }^{9}$

(10) Aal a mi breda-dem smáala dan mi.

[All of my brother-them smaller than me]

(todo de mi hermano-PL ser-más-pequeño que yo)

Todos mis hermanos son más pequeños que yo.

En el ejemplo anterior se reúnen todas las condiciones que propician el uso del marcador de plural con los nombres, ya que aparece un sustantivo con los rasgos [+definido], [+específico], [+animado], [+humano]. ${ }^{10}$

El marcador que expresa la categoría de número plural proviene del pronombre personal de tercera persona plural en esta lengua y es todavía idéntico a él. En esta misma lengua, el pronombre dem, aunque proviene del pronombre de objeto directo en inglés, tiene el valor tanto de sujeto como de objeto directo (cf. Dem kom liet [Them come late], Ellos llegaron tarde).

Ahora bien, en el ejemplo (10), dem no es en lo absoluto un pronombre. Es ya un marcador morfológico. De hecho, a diferencia de los pronombres determinativos en esta esta lengua, este aparece pospuesto al nombre que modifica.

Por otro lado, hay que mencionar que, en esta lengua, los pronombres personales tienen además una función determinativa, pues se utilizan de manera idéntica también como posesivos. Además, el pronombre de tercera persona plural puede tener un sentido también demostrativo, como en (11).

(11) Dem gyal príti.

[Them girl pretty]

(Esas muchacha ser-bonita)

Esas muchachas son bonitas.

El uso del pronombre de tercera persona plural para expresar la categoría de número plural es el resultado de varias operaciones de extensión metafórica, que tienen 
una base cognitiva evidente. El primer proceso de extensión metafórica involucra el concepto de [+definido]:

(f) Un pronombre personal de tercera persona plural es igual a un pronombre determinativo plural $>$ un pronombre determinativo plural modifica a un nombre definiéndolo > un nombre definido va a ser marcado por un operador de plural.

El segundo proceso de extensión metafórica está relacionado con el concepto de [+específico]:

(g) Un nombre definido por un determinante tiene carácter referencial > un nombre definido con carácter referencial es específico.

Esta operación metafórica tiene su base cognitivo-lingüística en el hecho de que los pronombres tienen un carácter eminentemente anafórico. Por lo tanto, siempre hacen referencia a entidades específicas.

Los siguientes ejemplos muestran cómo las propiedades de definido y específico permiten el uso (12) o no (13) del marcador de plural en el inglés criollo de Limón:

(12) Aal a di maskíta-dem bait aad.

[All of the mosquito-them bite hard]

(todo de el mosquito-PL picar duro)

Todos los mosquitos esos pican duro.

(13) Maskíta bait aad.

[Mosquito bite hard]

(mosquito picar duro)

Los mosquitos pican duro.

Es evidente que en (12) se trata de una entidad específica, mientras que en (13) la misma entidad no tiene carácter específico, sino más bien constituye una referencia genérica.

Como se ha dicho, el concepto de animicidad también es decisivo para el uso del marcador de plural. La relevancia de la propiedad de [+humano] es también el resultado de una operación de extensión metafórica. El pronombre de tercera persona plural (dem) relacionado con un nombre con el rasgo [+humano] conlleva la idea de que las entidades constituyen un grupo. Este tipo de relación se suele denominar plural asociativo (cf. Corbertt 2000: 10111), que quiere decir "X y otras personas asociadas con $X$ ". Un ejemplo (14) que ilustra este fenómeno puede ser apreciado a continuación en el húngaro (Corbertt 2000: 102):

(14) János-ék.

(Juan-PL-Asociativo)

Juan y su grupo.

En el inglés criollo de Limón, todavía es común el empleo de este plural asociativo, que es señalado con el mismo marcador del plural (-dem), como en (15) con dos variantes (Herzfeld 2002: 174).

(15) Kleoní-dem. // Kleoní an dem.

[Cleony them] // [Cleony and them]

(Cleony-PL) // (Cleony y ellas)

Cleony y otras como ella. 
La operación de extensión metafórica, entonces, puede ser expresada de la siguiente manera:

(h) Una entidad humana específica y su grupo > una entidad humana específica plural.

Se considera que el hecho de que los humanos sean naturalmente animados habría dado paso a que otros seres animados también pudieran ser incluidos dentro la categoría de las entidades pluralizables, propiciando que el rasgo [+animado] llegara a ser relevante.

(i) Una entidad humana animada específica plural > cualquier entidad animada específica plural.

Por otro lado, las propiedades de [+definido] o [+específico] permiten incluir también a los seres inanimados entre las entidades que pueden ser pluralizadas, aunque de manera menos prototípica:

(j) Una entidad animada definidal específica plural > una entidad inanimada definidal específica plural.

El proceso de extensión metafórica implícito en la redefinición de la categoría de número plural aplicada a los nombres en esta lengua habría implicado los siguientes cambios de énfasis en el concepto más central de la categoría:

(k) Una entidad humana animada específica definida $>$ una entidad no humana animada específica definida > una entidad animada o inanimada específica definida > una entidad animada o inanimada específica definida.

El ejemplo (16) muestra el uso del marcador de plural con nombres referidos a entidades inanimadas definidas y específicas. Este uso es mucho menos prototípico en el inglés criollo de Limón. El ejemplo (17) ilustra la referencia más común a entidades inanimadas aunque sean específicas y definidas, sin el marcador de plural.

(16) Mi bres-dem tu smaal.

[My breast-them too small]

(Mi seno-PL demasiado ser-pequeño)

Mis senos son demasiado pequeños.

(17) Mi bres tu smaal.

[My breast too small]

(Mi seno demasiado ser-pequeño)

Mis senos son demasiado pequeños.

Para el caso del inglés de Limón, se puede establecer entonces una jerarquía de rasgos semánticos para la marcación del plural en los nombres:

(l) Definido $>$ específico $>$ humano $>$ animado $>$ inanimado.

Por último, se debe mencionar que en esta lengua normalmente el uso de numerales y cuantificadores, que son operadores que definen al nombre, inhibe el uso del marcador de plural. La ausencia del marcador de plural se observa en los siguientes ejemplos (Herzfeld 2002: 215, 240): 
(18) An wen a put aan mi tuu fut in mai slípaz...

[And when I put-on my two foot in my slipers]

(Y cuando yo poner mi dos pie en mi pantuflas)

$Y$ cuando puse los dos pies en las pantuflas...

(19) So im yuustu av plénti foul in dier so laik ou.

[So him used-to have plenty fowl in there so like how]

(Entonces él HAB tener muchos gallina en ahí pues como cómo)

$Y$ él acostumbraba a tener muchas aves de corral allí, y de qué manera.

Es evidente que la marcación del número plural en estos casos es vacua, ya que los respectivos operadores informan al oyente sobre el número del nombre. Esta economía en el uso el operador de plural tiene, pues, también una evidente base cognitiva.

\subsection{La categoría de plural en otras lenguas criollas}

Hay que mencionar que todos estos procesos metafóricos descritos para el inglés criollo de Limón, que llevan a establecer las propiedades de la categoría de plural, son muy recurrentes en las lenguas criollas, independientemente de la base léxica de estas.

Por ejemplo, en papiamento, una lengua criolla de base ibérica y en criollo haitiano, de base francesa, sucede exactamente lo mismo: el marcador de plural en cada caso es idéntico al pronombre de tercera persona plural. En el caso del papiamento, el pronombre de tercera persona plural nan ha sido tomado presumiblemente de alguna lengua africana bantú (20) (Maurer 1998: 210). En criollo haitiano, el pronombre yo proviene del francés eux, el cual funciona como pronombre de objeto directo en esta lengua (21) (Heurtelou \& Vilsaint 2004:35).

(20) E kurso-nan nobo lo kuminsá e luna akí.

(ART-DEF curso-PL nuevo FUT comenzar ART-DEF luna aquí)

El nuevos cursos comenzarán este mes.

(21) Nan lang Kreyòl pwonon pèsonèl yo se: mwen, ou (wou), li, nou, yo.

(En lengua creóle pronombre personal PL ser: yo, vos, él/ella, nosotros/ ustedes, ellos/ellas)

En 'creóle' los pronombres personales son: yo, vos, éllella, nosotros/ustedes, ellos/ellas.

No solamente el uso del pronombre de tercera persona para expresar la categoría de plural es muy común en las lenguas criollas, sino también lo son las propiedades semánticas que son significativas en la conformación de la categoría de plural. En las lenguas particulares, los conceptos de [+definido], [+específico], [+humano], [+animado] son más o menos relevantes en cada caso.

En papiamento, por ejemplo, el concepto de [+definido] es la propiedad más central de la categoría (cf. Maurer 1998: 154) y las propiedades de [+ humano], [+animado] parecen no tener relevancia.

(22) E dos kabai-nan ku mi a mira.

(ART-DEF dos caballo-PL que yo PERF ver)

Los dos caballos que he visto. 
En otro ejemplo (Maurer 1998: 155), se nota que, al igual que en el inglés criollo de Limón, en papiamento, el rasgo [+específico] tiene más relevancia que la propiedad de [+animado] para la marcación del plural. Por ello, en (23) el nombre perro aparece sin la marcación de plural, ya que, en este caso, se trata de una referencia genérica, no específica, aunque obviamente el nombre se refiera a una entidad animada.

$$
\begin{aligned}
& \text { Kachó tin kuater pia. } \\
& \text { (Perro tener cuatro pata) } \\
& \text { Los perros tienen cuatro patas. }
\end{aligned}
$$

Además, los dos ejemplos anteriores muestran que el empleo del marcador de plural con numerales depende de que si el nombre es [+definido] o no (Maurer 1998: 154).

Asimismo, como se ha dicho, en otras lenguas criollas, el marcador de plural no proviene del pronombre de tercera persona plural. Por ejemplo, en palenquero, un criollo de base española hablado en Colombia, y en holandés de Berbice, un criollo obsolescente utilizado en Guyana, los marcadores de plural provienen de operadores existentes ya en las lenguas africanas de sustrato.

En palenquero, el marcador es la partícula clítica $m a-$, la cual proviene de un prefijo nominal de clase plural del kikongo (familia bantú) (cf. Schwegler 1998: 245; 259 y ss.). En holandés de Berbice, el marcador es el sufijo - $a p(u)$, el cual proviene también de un sufijo nominal de clase plural en ijo oriental (familia ijoide) (cf. Arends, Kouwenberg \& Smith 1995: 105). A pesar de ello, en ambas variedades, también las propiedades de [+definido] y [+específico] parecen ser centrales en la categorización del plural.

En palenquero, el ejemplo (24) presenta un nombre con el rasgo [+específico], pero [-definido]. En el ejemplo (25) aparece un nombre [+definido] y [+específico]. ${ }^{11}$

(24) Y-a miná un ma kasa aí.

(yo PDO ver ART-IND PL casa ahí)

Vi unas casas ahí.

(25) Ma besinu ele, ¿kumu asé nyamá?

(PL vecino 3sing. cómo HAB llamar)

Sus vecinos, ¿cómo se llaman?

Sin embargo, cuando se trata de nombres con el rasgo [-específico] (26) o acompañados de numerales (27) o cuantificadores (28), no se utiliza el marcador de plural, se trate de seres animados o no. ${ }^{12}$

(26) A..., sútu á tá kumo guandaná.

(Ah nosotros T/A ser como araña)

Ah, nosotros somos como las arañas.

(27) Y á tén séi moná.

(yo T/A tener seis hijo)

Tengo seis hijos.

(28) Akí Palénge súto a tén baria família ríko.

(Aquí Palenque 1pl. T/A tener varios familia riko)

En nuestro Palenque hay varias familias ricas. 
Pero, si se trata de un nombre con los rasgos [-especifico] pero [+humano], es posible utilizar el marcador de plural, aunque esto sucede de manera menos prototípica. ${ }^{13}$

(29) Ma moná tá má ngánde ku riesiséi.

(PL muchacho estar más grande con dieciséis)

Los muchachos (en general) están más grandes con dieciséis.

Por otro lado, en holandés de Berbice, el marcador de plural - ap $(u)$ se utiliza en (30) porque se trata de un nombre [+definido], [+específico]. Pero se omite en (31) cuando el nombre es [-definido], [-específico]. ${ }^{14}$

(30) Ju kiki di gutw-ap di ka.

(Usted ver ART-DEF cosa-PL este no)

Usted (ya) no ve estas cosas.

(31) Wel hir were, ju das deki gutu pi ju mati.

(Bien aquí nuevamente, usted HAB tomar cosa dar 2sing. amigo)

Bueno, aquí de nuevo, usted les da cosas a sus amigos.

Además, al igual que en el inglés criollo de Limón, en el holandés de Berbice, la categoría de plural incluye el uso del plural asociativo, como en (32) (Kouwenberg 1994: 544)

(32) Eke фap-ap kum, mutð danð nau.

(1sing. padre-PL venir, ir-PERF allí ahora)

Mi papá y la gente de su generación se fueron allí ahora.

Igualmente, el marcador se omite cuando el nombre va acompañado de numerales (33) o cuantificadores (34), aunque se trate de nombres con el rasgo [+definido]. ${ }^{15}$

(33) Wel di twe jungjerm wat je di wari ben...

(Bien ART-DEF dos jóven-mujer que estar ART-DEF casa en)

Bueno, las dos muchachas que viven en la casa.

(34) An kom bring musu bambam gut.

(Y venir traer muchos bonito cosa)

$Y$ traen muchas cosas bonitas.

Por otra parte, se puede analizar también el caso del chabacano, que es un criollo de base española hablado en las islas Filipinas. Como se ha dicho, en este criollo el marcador de plural manga o maga es una partícula que está relacionada diacrónicamente con el cuantificador muchos. Se coloca antes del nombre que determina. ${ }^{16}$

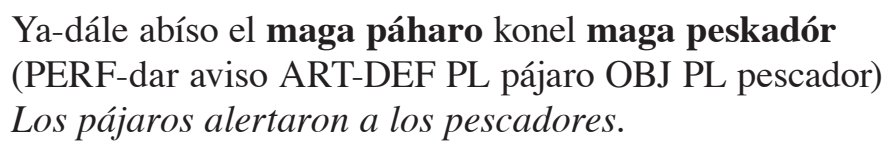

Ya-dále abíso el maga páharo konel maga peskadór (PERF-dar aviso ART-DEF PL pájaro OBJ PL pescador)

Los pájaros alertaron a los pescadores.

Este marcador está tomado con seguridad del tagalo y su uso en el chabacano parece ser similar en ciertos aspectos al que este tiene en aquella lengua. De cualquier forma, el rasgo de [+definido] en los nombres parece ser crucial para el empleo del marcador de plural, como se nota en el ejemplo anterior.

Por otro lado, la descripción que lleva a cabo Grant (2007) muestra algunas diferencias sustanciales entre el chabacano y el tagalo. Es especialmente significativo que el 
chabacano no permita el uso del marcador de plural si aparece un numeral en la cláusula, al igual que sucede en otras lenguas criollas descritas aquí, pero a diferencia del tagalo, donde esto sí es permitido. ${ }^{17}$

(36) Para dos aak grande gayot dimyo.

(Para dos hijo grande muy de-mí)

Para mis dos muy grandes hijos.

Es también significativo que, a diferencia del español y del tagalo, el chabacano utilice de manera facultativa el marcador de plural cuando se trata de nombres indefinidos. Esto podría indicar que los rasgos de [+definido] y [+especifico] son igualmente relevantes en esta lengua para determinar el uso del marcador de plural, tal como parece suceder prototípicamente en gran parte de las lenguas criollas (cf. Grant 2007: 204, apéndice I).

\section{Conclusiones}

En este trabajo se ha pretendido mostrar cómo las categorías gramaticales son construidas a partir de operaciones de extensión metafórica. Se ha visto cómo las lenguas criollas, por su naturaleza, ofrecen un campo muy fructífero para la exploración de la base cognitiva de las propiedades de categorías básicas en las lenguas del mundo.

En el caso de la categoría de plural analizada aquí, es significativa la relevancia de las propiedades de [+definido], [+específico], [+humano], [+animado], elaboradas a partir de operaciones metafóricas con una fuerte base cognitiva.

Así mismo, existen otros patrones que son recurrentes en las lenguas criollas, como la existencia de un plural asociativo o la tendencia a no emplear el marcador de plural cuando el nombre va acompañado de numerales o cuantificadores.

Es también muy notable que muchas lenguas criollas tomen el operador de la categoría de plural del pronombre de tercera persona plural de la propia lengua, independientemene de la base léxica que tengan.

\section{Notas}

1 "Ir a un lugar donde uno va a hacer X > trasladarse a un tiempo donde uno va a hacer X".

2 La colocación pospuesta del verbo auxiliar es normal en el español antiguo, como se ilustra en los ejemplos que se mencionarán.

3 Cras a la mañana significa mañana por la mañana.

$4 \quad$ Cf. Comrie 1985: 43 y ss.

5 Cf. Palmer 2001: 1 y ss.

6 Sin embargo, también existen diversos pidgins, especialmente los denominados pidgins extendidos o estabilizados, que utilizan sistemáticamente la marcación del plural (cf. Bakker 2002: 15-16). 
9 Los ejemplos del inglés criollo de Limón son tomados de los datos de trabajo de campo del autor de este artículo, a no ser que se indique lo contrario. Vaya mi agradecimiento para la Marcia Reid Chambers por su invaluable y generosa colaboración.

10 Para una definición de los conceptos de definido y específico (o referencial), cf. Givón 1984: 388 y ss.

11 Los ejemplos son tomados de Schwegler 1998: 261.

12 Los ejemplos son tomados de Schwegler 1998: 258, 259 y Schwegler \& Hualde 2008:19.

13 El ejemplo es tomado de Schwegler 2007: 219, nota 25. Este autor, sin embargo, menciona este ejemplo con el fin de mostrar que these articles [ma es consderado un artículo definido plural] are nonobligatory, and, therfore, seemingly non-predictable components.

$14 \quad$ Los ejemplos son tomados de Kouwenberg 1994: 238 y 398.

$15 \quad$ Los ejemplos son tomados de Kouwenberg 1994:158 y 159.

$16 \quad$ El ejemplo es tomado de Forman 1972: 157.

17 Cf. el siguiente ejemplo en tagalo: Ang tatlot-ng manga aso (DEF tres-LIG PL perro) Tres perros. El ejemplo del chabacano es tomado de Grant 2007:185.

\section{Abreviaturas}

$\begin{array}{ll}\text { ART-DEF } & \text { Artículo definido } \\ \text { ART-IND } & \text { Artículo indefinido } \\ \text { HAB } & \text { Aspecto habitual } \\ \text { LIG } & \text { Ligadura } \\ \text { OBJ } & \text { Marcador de objeto } \\ \text { PDO } & \text { Tiempo pasado } \\ \text { PERF } & \text { Perfecto } \\ \text { PL } & \text { Plural } \\ \text { PRO } & \text { Aspecto progresivo } \\ \text { T/A } & \text { Marcador de tiempo y aspecto }\end{array}$

\section{Bibliografía}

Arends, Jacques, Silvia Kouwenberg \& Norval Smith. 1995. "Theories focusing on the non-European input". En: Arends, Muysken \& Smith (eds.), 87-109.

Arends, Jacques, Pieter Muysken \& Norval Smith. 1995. Pidgins and creoles. Ámsterdam/ Filadelfia: John Benjamins. 
Bakker, Peter. 2002. "Pidgin inflectional morphology and its implications for creole morphology." En: Booij \& Van Marle (eds.), 3-33.

Baptista, Marlyse \& Jacqueline Guéron (eds.). 2007. Noun phrases in creole languages. A multi-faceted approach. Ámsterdam/Filadelfia: Benjamins.

Bickerton, Derek. 1988. "Creole language and the bioprogram.” En: Newmeyer (ed.), 268-284.

Booij, Geert \& Jaap Van Marle (eds.). 2002. Yearbook of morphology. Dordrecht: Kluwer Academic Publishers.

Comrie, Bernard. 1985. Tense. Cambridge: Cambridge UP.

Corbett, Greville. 2000. Number. Cambridge: Cambridge UP.

Crawfurd, John. 1852. A grammar and dictionary of the Malay language with a preliminary dissertation. Londres: Smith, Elder and Co.

Del Castillo, Nicolás. 1984. "El léxico negro-africano de San Basilio de Palenque". Tesaurus. 39: 80-169.

Forman, Michael. 1972. Zamboangueño texts and grammatical analysis. A study of Philippine Creole Spanish. Tesis doctoral: Universidad de Cornell.

Givón, Talmy. 1984. Syntax: A functional-typological introduction. Volumen I. Ámsterdam/ Filadelfia: John Benjamins.

Grant, Anthony. 2007. "Some aspects of NPs in Mindanao Chabacano." En: Baptista \& Guéron (eds.), 173-204.

Herzfeld, Anita. 2002. Mekaytelyuw. La lengua criolla. San José: Editorial de la Unversidad de Costa Rica.

Heurtelou, Maude \& Féquière Vilsant. 2004. Guide to learning Haitian Creole. Coconut Creek: Educa Vision.

Holm, John. 1989. Pidgins and creoles. Volumen II. Cambridge: Cambridge UP.

Hualde, José Ignacio \& Armin Schwegler. 2008. “Intonation in Palenquero.” Journal of Pidgin and Creole languages. 23: 1-31.

Kouwenberg, Silvia. 1994. A grammar of Berbice Dutch Creole. Berlín: Mouton de Gruyter. 
1995. “Berbice Dutch”. En: Arends, Muysken \& Smith (eds.), 233-243.

Maurer, Philippe. 1998. “El papiamento de Curazao”. En: Perl \& Schwegler (eds.), 139-217.

Newmeyer, Frederick (ed.). 1988. Linguistics. The Cambridge survey. Volume 2. Linguistics theory: Extensions and implications. Cambridge: Cambridge UP.

Palmer, Frank Robert. 2001. Mood and modality. Cambridge: Cambridge UP.

Perl, Matthias \& Armin Schwegler (eds.). 1998. América negra: Panorama actual de los estudios lingüísticos sobre variedades hispanas, portuguesas y criollas. Francfort/ Madrid: Vervuert/Iberoamericana.

Schwegler, Armin. 1998. "El palenquero”. En: Perl \& Schwegler (eds.), 219-291.

2007. "Bare nouns in Palenquero: A fresh consensus in making." En: Baptiste \& Guéron (eds.), 205-222.

Wittgenstein, Ludwig. 1953. Philosophical Investigations. Nueva York: Macmillan. 